International Journal of Advanced Chemistry, $9(2)(2021) 70-73$
International Journal of Advanced Chemistry
SPC
Website: www.sciencepubco.com/index.php/IJET
Research paper

\title{
Influence of solvents on polyphenol content and antioxidant activity of fig leaf extracts obtained by maceration and ultrasonic extraction
}

\author{
Sabina Merzić ${ }^{1}$ *, Ajla Šehanović ${ }^{1}$, Amila Mušić ${ }^{1}$, Asim Šarić ${ }^{1}$, Mehmed Alić ${ }^{1}$, Ajla Avdić ${ }^{1}$, \\ Almina Huskić ${ }^{1}$, Basaryusuf Yazici ${ }^{1}$, Maida Bašić ${ }^{1}$, Ivana Pavić ${ }^{1}$, Emir Horozić ${ }^{2}$ \\ ${ }^{1}$ Department of Food Technology, Faculty of Tecnology, University of Tuzla, Urfeta Vejzagića 8, 75000 Tuzla, B\&H \\ ${ }^{2}$ Department of Organic Chemistry, Faculty of Technology, University of Tuzla, Urfeta Vejzagića 8, 75000 Tuzla, B\&H \\ *Corresponding author E-mail: sabina.merzic@gmail.com
}

\begin{abstract}
In this paper, the polyphenol content and antioxidant activity of fig leaf extracts were analyzed. Extraction was performed with methanol, ethanol, acetone and their aqueous mixtures $(50: 50 \mathrm{v} / \mathrm{v})$. Extractions were performed with stirring at $300 \mathrm{rpm}$ on a vibromix and ultrasonic bath for 15 minutes. The polyphenol content was determined spectrophotometrically using the Folin-Ciocalteu test. Antioxidant capacity was tested using the FRAP and DPPH methods. The results showed a significant effect of extraction of bioactive components using an organic solvent:water mixture in relation to the organic solvent itself. Ultrasonic extraction proved to be a more efficient technique compared to mixing at $300 \mathrm{rpm}$.
\end{abstract}

Keywords: Fig Leaf; Polyphenols; FRAP; DPPH Inhibition.

\section{Introduction}

Ficus carica (common fig) is a tree native to southwest Asia and the eastern Mediterranean and is among the first plants cultivated by humans (Kucukerdonmez et al., 2021). F. carica L. is an important member of the genus Ficus. The fig is an important harvest worldwide for its dry and fresh consumption (Mawa et al., 2013). Figs are rich in carbohydrates, minerals, and bioactive compounds, among other properties. In addition, some compounds can be found in the leaves (Garza-Alonso et al., 2019). Medicinal plants belonging to the genus Ficus have been reported as better remedies for metabolic disorders (Mopuri et al., 2018). F. carica has been reported to have numerous bioactive compounds such as arabinose, $\beta$-amyrins, $\beta$ - carotenes, glycosides, $\beta$-sitosterol and xanthotoxol (Kannur and Khandelwal, 2014). Organic acids profile of fig leaves is composed by six organic acids: oxalic, citric, malic, quinic, shikimic, and fumaric acids (Oliveira et al., 2009). F. carica fruit phytochemical such as 6-O-acyl- $\beta$-D-glucosyl- $\beta$-sitosterol was reported as a potential cytotoxic agent and the latex of fig demonstrated the inhibition of cancer cell proliferation (Lazreg et al., 2011; Rubnov et al., 2001). Fig leaf extract has been found to have good antioxidant, anti-inflammatory and hepatoprotective activity (Mopuri et al., 2018).

In this paper, the influence of extraction technique and different organic solvents and their aqueous mixtures on antioxidant capacity and polyphenol content is analyzed. This research can help in a better understanding of the extraction conditions for the extraction of bioactive components from this plant.

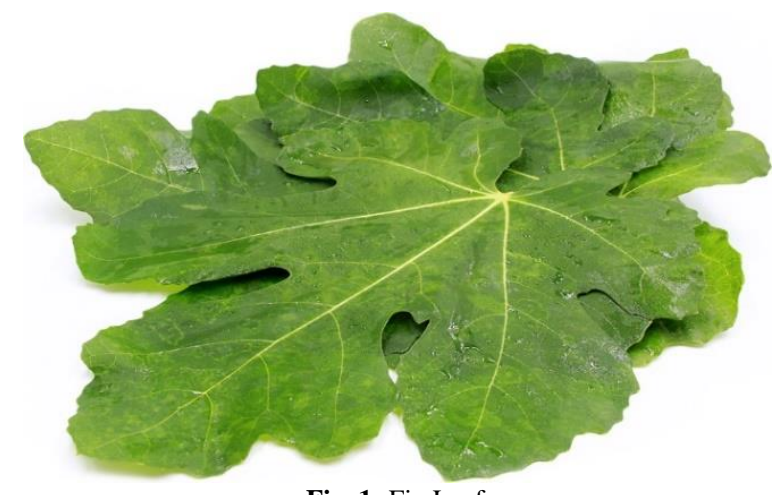

Fig. 1: Fig Leaf. 


\section{Material and methods}

Dried fig leaves were bought in one of the Tuzla markets. The leaves were ground to a powder using an electric grinder and subjected to extraction in this form. Ultrapure water, prepared with a TKA Smart2Pure device, was used for the extraction process. Methanol, glacial acetic acid, hydrochloric acid, sodium carbonate were purchased from Merck (Darmstadt, Germany). 2,2`-diphenyl-1-picrylhydrazyl (DPPH), gallic acid and 2,4,6-tris(2-pyridyl)-s-triazine (TPTZ) were obtained from Sigma Chemical Co. (St. Louis, Missouri, USA). Iron(II) sulphate heptahydrate and iron(III) chloride hexahydrate were purchased from Honeywell (Charlotte, North Carolina, USA). Folin \& Ciocalteu's reagent was purchased from Semikem (Bosnia and Herzegovina).

\subsection{Preparation of extracts}

1 gram of powdered fig leaves was transferred to a flat-bottomed flask and poured with $50 \mathrm{~mL}$ of organic solvent or organic solvent: water mixture $(50: 50 \mathrm{v} / \mathrm{v})$. Maceration was performed with stirring at $300 \mathrm{rpm}$ on a Libra 40 vibromix. Ultrasonic extraction was performed in an Elmasonic S ultrasonic bath. Extraction was performed for 15 minutes in the case of both extraction techniques. After the extraction, the mixture was filtered through a blue strip of filter paper and the obtained extracts were immediately analyzed.

\subsection{Determination of total phenolic content (TPC)}

Total phenolic compounds presented in the extracts were quantified spectrophotometrically using the Folin-Ciocalteu test following the protocol (Singleton et al., 1999), with some modifications. $200 \mu \mathrm{L}$ of extracts was mixed with $2.54 \mathrm{~mL}$ of $10 \%$ Folin-Ciocalteu reagent. After $5 \mathrm{~min} 420 \mu \mathrm{L}$ of $10 \%$ sodium carbonate was added. The absorbance of the resulting blue-coloured solution was measured at $765 \mathrm{~nm}$ after incubation at room temperature for 1 hour. Quantitative measurements were performed, based on a standard calibration curve of gallic acid $\left(y=0,0042 x+0,0076, R^{2}=0,9998\right)$. The total phenolic content was expressed as gallic acid equivalents (GAE) in milligrammes per gram of fig leaves.

\subsection{Ferric-reducing antioxidant power (FRAP) assay}

The reducing powers of the extracts that reflected their antioxidant activity were determined following the protocol (Benzie and Strain, 1999). $3 \mathrm{~mL}$ of prepared FRAP reagent is mixed with $100 \mu \mathrm{L}$ of extracts. Absorbance at $593 \mathrm{~nm}$ is recorded after a 30 min incubation at $37^{\circ} \mathrm{C}$. The FRAP value was calculated from the calibration curve of iron (II) sulfate heptahydrate $\left(y=0,001 x+0,0698 ; R^{2}=0,9997\right)$ and expressed in mol per gram of fig leaves.

\subsection{DPPH radical scavenging activity}

2,2-diphenyl-1-picryl-hydrazyl (DPPH) method was performed according to earlier described method (Horozić et al., 2019). 100 $\mu \mathrm{L}$ of the diluted extract was mixed with $1900 \mu \mathrm{L}$ of methanol and $500 \mu \mathrm{L}$ of $0.5 \mathrm{mM}$ DPPH radical solution. The absorbance was measured at 517 $\mathrm{nm}$ with methanol as a blank sample. $0.5 \mathrm{~mL}$ of $0.5 \mathrm{mM} \mathrm{DPPH}$ dilution, diluted with $4 \mathrm{~mL}$ of methanol, was used as a control sample. The radical scavenging effect $(\%)$ or percent inhibition of DPPH radical was calculated according to the equation:

$[(\mathrm{Ac}-\mathrm{As}) / \mathrm{Ac}] \mathrm{x} 100$

Where As is the absorbance of the solution containing the sample at $517 \mathrm{~nm}$ and Ac is the absorbance of the DPPH solution.

\section{Results and discussion}

Tables 1 and 2 show the results of polyphenol content and antioxidant activity of the prepared extracts in vitro. The highest polyphenol content in the case of both extraction techniques has the water-ethanol extract, followed by the water-acetone and water-methanol extract. The weakest effect in the extraction of bioactive components was shown by acetone, whose extract showed significantly the lowest polyphenol content and at the same time the weakest antioxidant activity.

Table 1: Results of Analysis of Polyphenol Content, Reduction Ability and Inhibition of DPPH Radicals for Extracts Obtained by Ultrasonic Extraction

\begin{tabular}{llll}
\hline Extract & TPC $[\mathrm{mg} \mathrm{GAE} / \mathrm{g}]$ & FRAP $[\mu \mathrm{mol} / \mathrm{g}]$ & $\mathrm{IC}$ ) \\
\hline Methanol & 3.45 & 26.9 & 2.08 \\
Ethanol & 2.48 & 13.7 & 3.51 \\
Acetone & 1.62 & 13.9 & 9.07 \\
Methanol:Water & 9.47 & 99.9 & 0.49 \\
Ethanol:Water & 12.8 & 129.8 & 0.39 \\
Acetone:Water & 10.9 & 120.8 & 0.41 \\
\hline
\end{tabular}

Table 2: Results of Analysis of Polyphenol Content, Reduction Ability and Inhibition of DPPH Radicals for Extracts Obtained by Maceration

\begin{tabular}{llll}
\hline Extract & TPC $[\mathrm{mg} \mathrm{GAE} / \mathrm{g}]$ & FRAP $[\mu \mathrm{mol} / \mathrm{g}]$ & $\mathrm{IC}$ ) \\
\hline Methanol & 2.13 & 26.3 & 2.58 \\
Ethanol & 1.34 & 13.5 & 3.82 \\
Acetone & 1.04 & 12.9 & 10.0 \\
Methanol:Water & 8.58 & 90.1 & 0.68 \\
Ethanol:Water & 9.01 & 120.0 & 0.51 \\
Acetone:Water & 8.86 & 119.1 & 0.59 \\
\hline
\end{tabular}

The order of extraction efficiency of the bioactive components decreases in the following order: water-ethanol mixture > water-acetone mixture > water-methanol mixture > methanol > ethanol > acetone. It was found that when extracting bioactive components from dry plant material, a better effect is achieved by a higher proportion of the aqueous phase in the organic (Bimakr et al., 2011). Water increases the diffusion process, thus facilitating the extraction of phenolic compounds from plant tissue (Altiok et al., 2008). 
Abdel-Aziz et al. (2020) examined fig leaf extracts. Water was used as the extraction solvent. The aqueous extract was shown to be more effective in neutralizing DPPH radicals, with an $\mathrm{IC}_{50}$ value of $30 \mu \mathrm{g} / \mathrm{mL}$. The reason for better results can be explained by the different geographical origin of fig leaves, the method of extraction, etc.

Comparison of the content of isolated polyphenols and antioxidant activity using two extraction techniques is shown in Figures 2 and 3. Higher efficiency in isolating biologically active components was recorded using ultrasonic extraction. This can be explained by the effect of cavitation on the cell material, more precisely the cell wall, which allows greater penetration of the solvent into the material and increases the mass transfer. Due to the rupture of the cell walls, there is a direct contact with the contents of the cell, which accelerates the extraction and increases its efficiency.

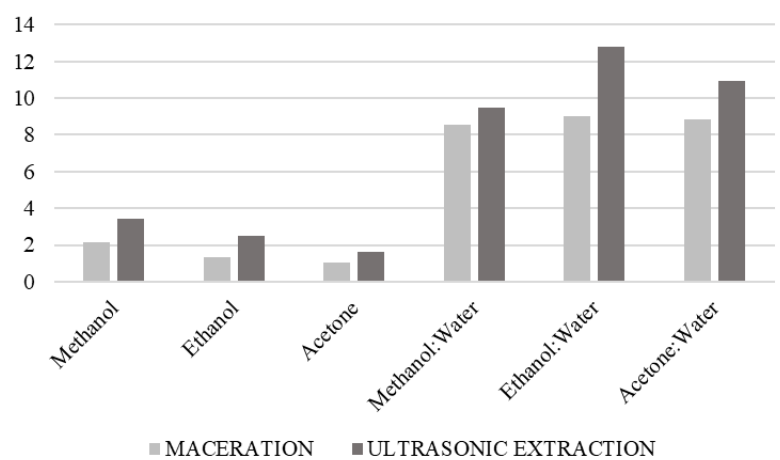

Fig. 2: Comparison of Polyphenol Contents Obtained by Maceration and Ultrasonic Extraction.

(A)

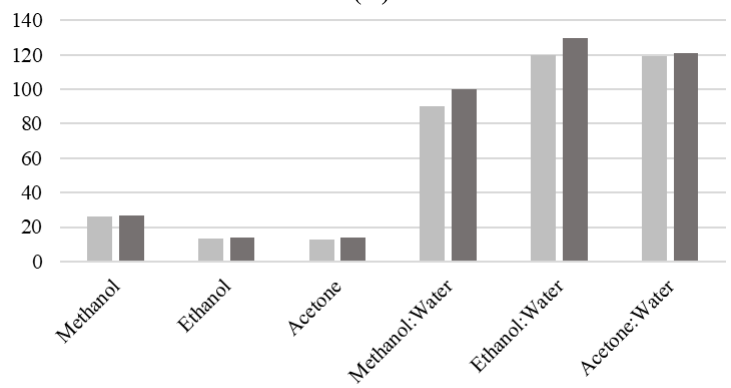

MACERATION ULTRASONIC EXTRACTION
(B)

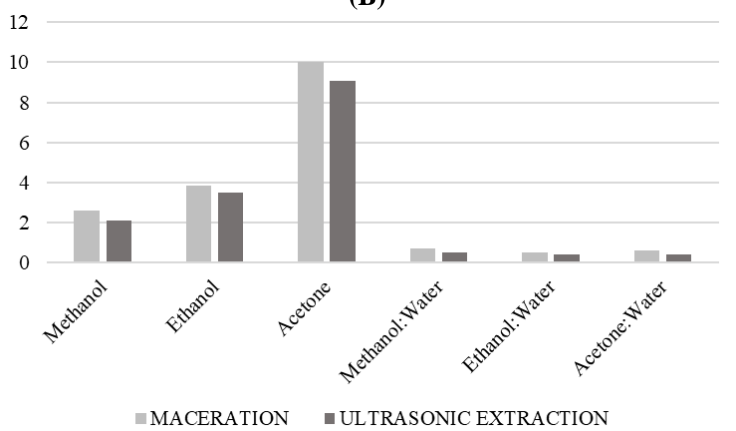

Fig. 3: Comparison of (A) Reduction Ability and (B) Inhibition of DPPH Radicals for Fig Leaf Extracts Obtained by Maceration And Ultrasonic Extraction

\section{Conclusion}

Based on the performed analysis, it is concluded that the extracts obtained by mixing organic solvents with water have a higher polyphenol content and higher antioxidant activity compared to the extracts obtained with the organic solvents themselves. The best results in the extraction of bioactive components were shown by the mixture of ethanol:water, in the case of both extraction techniques. Acetone showed the weakest extraction potential. By comparing extraction techniques, ultrasonic extraction proved to be more efficient.

\section{References}

[1] Abdel-Aziz MD, Darwish MS, Mohamed AH, El-Khateeb AY \& Hamed SE (2020), Potential Activity of Aqueous Fig Leaves Extract, Olive Leaves Extract and Their Mixture as Natural Preservatives to Extend the Shelf Life of Pasteurized Buffalo Milk. Foods 9(5), 615. https://doi.org/10.3390/foods9050615.

[2] Altiok E, Bayçin D, Bayraktar O \& Ülkü S (2008), Isolation of polyphenols from the extracts of olive leaves (Olea europaea L.) by adsorption on silk fibroin. Separation and Purification Technology 62, 342-348. https://doi.org/10.1016/j.seppur.2008.01.022.

[3] Benzie IFF, Strain JJ (1999), Ferric reducing/antioxidant power assay: direct measure of total antioxidant activity of biological fluids and modified version for simultaneous measurement of total antioxidant power and ascorbic acid concentration. Methods in Enzymology 299, 15-27. https://doi.org/10.1016/S0076-6879(99)99005-5.

[4] Bimakr M., Rahman RA, Taip FS, Ganjloo A, Salleh LM, Selamat J, Hamid A \& Zaidul ISM (2011), Comparision of different extraction methods for the extraction of major flavonoid compounds from spearmint (Mentha spicata L.) leaves. Food and Bioproducts Processing 89, 67-72. https://doi.org/10.1016/j.fbp.2010.03.002.

[5] Garza-Alonso CA, Olivares-Sáenz E, Gutiérrez-Díez A, Vázquez-Alvarado RE \& López-Jiménez A (2019), Visual Symptoms, Vegetative Growth, and Mineral Concentration in Fig Tree (Ficus carica L.) Under Macronutrient Deficiencies. Agronomy 9(12), 787. https://doi.org/10.3390/agronomy9120787.

[6] Horozić E, Zukić A, Kolarević L, Bjelošević D, Ademović Z, Šarić-Kundalić B, Husejnagić D, Kudumović A, Hamzić S (2019) Evaluation of antibacterial and antioxidant activity of methanol needle extracts of Larix Decidua Mill., Picea Abies (L.) H. Karst. and Pinus Nigra J. F. Arnold. Technics Technologies Education Management 14(1), 14-19.

[7] Kannur D \& Khandelwal K (2014), Pharmacognostical investigation and evaluation of Ficus carica fruit extract for adaptogenic activity. International Journal of Pharmaceutical Sciences and Research 5(5), 2022-2032. https://doi.org/10.13040/IJPSR.0975-8232.5(5).2022-32.

[8] Kucukerdonmez O, Baygeldi N, Akder RN \& Çağındı Ö (2021), Medicinal and Nutritional Analysis of Fig (Ficus carica) Seed Oil; A New Gamma Tocopherol and Omega-3 Source. Progress in Nutrition 23(2), 1-6.

[9] Lazreg Aref H, Gaaliche B, Fekih A, Mars M, Aouni M, Pierre Chaumon J, Said K (2011), In vitro cytotoxic and antiviral activities of Ficus carica latex extracts. Natural Product Research, 25(3), 310-319. https://doi.org/10.1080/14786419.2010.528758.

[10] Mawa S, Husain K \& Jantan I (2013), Ficus carica L. (Moraceae): Phytochemistry, Traditional Uses and Biological Activities. Evidence-Based Complementary and Alternative Medicine 2013. https://doi.org/10.1155/2013/974256. 
[11] Mopuri R, Ganjayi M, Meriga B, Koorbanally NA \& Islam S (2018), The effects of Ficus carica on the activity of enzymes related to metabolic syndrome. Journal of Food and Drug Analysis 26(1), 201-210. https://doi.org/10.1016/j.jfda.2017.03.001.

[12] Oliveira AP, Valentão P, Pereira JA, Silva BM, Tavares F, Andrade PB (2009), Ficus carica L.: Metabolic and biological screening. Food and Chemical Toxicology 47(11), 2841-2846. https://doi.org/10.1016/j.fct.2009.09.004.

[13] Rubnov S, Kashman R, Rabinowiz M, Schlesinger M, Mechoulam R (2001) Suppressors of cancer cell proliferation from fig (Ficus carica) resin: isolation and structure elucidation. Journal of Natural Products 64(7), 993-996. https://doi.org/10.1021/np000592z.

[14] Singleton VL, Orthofer R, Lamuela-Raventós RM (1999), Analysis of total phenols and other oxidation substrates and antioxidants by means of folin-ciocalteu reagent. Methods in Enzymology 299, 152-178. https://doi.org/10.1016/S0076-6879(99)99017-1. 